\title{
La literatura valida la acción: los géneros fic- cionales en la prosa historiográfica de Bernal Díaz del Castillo ${ }^{1}$
}

\author{
Gloria CHICOTE \\ IdIHCS (UNLP-CONICET) Argentina
}

\begin{abstract}
RESUMEN
El presente artículo propone analizar los contactos entre géneros y prácticas discursivas. Con ese objetivo en primer lugar se reflexiona sobre el concepto de verdad, su relación con la intertextualidad y las realizaciones discursivas, tal como es tratado por la teoría historiográfica. En segundo término, el núcleo de este artículo constituye en el rastreo e interpretación de estas marcas compositivas en la Historia verdadera de la conquista de la Nueva España de Bernal Díaz del Castillo, con mención particular a la presencia del romancero.
\end{abstract}

Palabras clave: crónicas de indias, historiografía, romancero, intertextualidad

\section{Literature validates action.}

Genres of fiction in Bernal Díaz del Castillo's historiographic prose

\begin{abstract}
The article deals with the way in which different genres and discoursive praxis come into contact. In this sense, it first reflects on the concept of truth such as it is treated in historiographic theory, focusing on its relations to intertextuality and its discoursive manifestations. Second, the article examines the concrete appearance of this problematic in Bernal Díaz del Castillo's Historia verdadera de la conquista de la Nueva España by bringing into light its constitutive features and paying special attention to the role of the romancero in historiographic praxis.
\end{abstract}

Keywords: Chronicles of Indias, Historiography, Romancero, Intertextuality

SUMARIO: 1. Preliminares. 2. Apuntes historiográficos. 3. La Historia verdadera...: una posible lexicalización de la experiencia.

${ }^{1}$ Una versión introductoria de este artículo fue expuesta en el marco del Seminario "Crónicas de Indias e intertextualidad" el 1 de abril de 2011 en la Universidad Complutense de Madrid. El presente texto recoge los aportes que en esa oportunidad hicieron la anfitriona y directora del Seminario, Esperanza López Parada, los colegas y estudiantes presentes. Gracias a todos por la pertinencia de sus observaciones. 


\section{Preliminares}

Las presentes reflexiones sobre la historiografía de Indias tienen como punto de partida un conjunto de estudios que llevé a cabo sobre la relación oralidad - escritura y las marcas de ficcionalización de la historia en la literatura tradicional - popular. Desde ese ángulo, estas indagaciones en las estrategias de intertextualidad se hallan en conexión con otras previas referidas a la Edad Media, tales como dos artículos dedicados a las representaciones de Inés de Castro (Chicote, 1999) y Pedro el Cruel (Chicote, 2006 y 2010), o procesos semejantes analizados en la literatura popular rioplatense de fines del siglo XIX (Chicote, 2007 y 2009). ${ }^{2}$

Con el propósito de analizar los contactos entre géneros y prácticas discursivas, me detendré en primer lugar en algunas reflexiones sobre la teoría historiográfica, con especial atención en la definición del concepto de verdad y su relación con la intertextualidad y las realizaciones discursivas. El núcleo de este artículo constituye en el rastreo e interpretación de estas marcas compositivas en la Historia verdadera de la conquista de la Nueva España de Bernal Díaz del Castillo, con mención particular a la presencia del romancero.

\section{Apuntes historiográficos}

El descubrimiento y la conquista de América tuvieron casi paralelamente a su realización un correlato discursivo. Contamos con testimonios de las acciones e impresiones suscitadas por el Nuevo Mundo a través del Diario de Cristóbal Colón, las Cartas de relación de Hernán Cortés y, a partir de ellos, con múltiples escritos que desde España o América, procedentes de la pluma de testigos presenciales o de cronistas profesionales, dan cuenta de hechos y situaciones según diferentes visiones del proceso que atienden a intereses puntuales de orden político, religioso y de reivindicación de posiciones individuales.

Como punto de partida podemos afirmar que la crónica de Indias es un subgénero de la historiografía española aparecido a fines del siglo XV, paralelamente a los primeros viajes, y continuado con textos de composición y finalidades muy diversas hasta finales del siglo XVIII, cuando los escritos de los jesuitas exiliados aparecen como documentos epilogares.

Durante todo este período la incursión en América amplió el horizonte europeo de manera revolucionaria, abrió el espacio en términos epistemológicos y conllevó

\footnotetext{
${ }^{2}$ Estos trabajos se inscriben a su vez en los lineamientos marcados por los estudios clásicos de Ramón Menéndez Pidal y Diego Catalán y se pueden ejemplificar en trabajos más recientes que conectan romancero e historiografía como el de Pedro Ferré sobre la muerte de la duquesa de Braganza (Ferré, 1983), o el de Valenciano (en prensa) sobre el rey don Pedro.
} 
el gran desafío de dar forma a experiencias extremadamente novedosas, ${ }^{3}$ que por un lado se inscriben en la historiografía española en general, ${ }^{4}$ y por otro, se distinguen de ella por el tratamiento de una materia, cuya primicia no se circunscribe a sí misma sino que también confronta a los autores con la necesidad de activar cambios formales.

La estrategia utilizada para la redacción de los textos historiográficos constituyó, sin lugar a dudas, en echar mano del bagaje cultural previo y probar su eficacia para efectuar la descripción, la narración y el análisis de un contenido desconocido. El resultado fue la confluencia de tradiciones discursivas procedentes de la jurisprudencia o el ámbito científico, junto con otras de raigambre ficcional como las novelas de caballerías, los libros de viajes o géneros estrictamente vinculados con la comunicación oral como el romancero y el refranero. La validez de ese conjunto de saberes, que en todos los casos eran anteriores a la concepción de los textos, se transmitió a partir de las formas textuales vigentes que aportaron sus procedimientos $\mathrm{y}$, a la vez, produjeron cambios de perspectivas y desarrollaron nuevas prácticas escriturales.

Una parte de la crítica sostuvo la presencia de esta tradición a través de modelos implícitos que abrían seguido los cronistas para escribir la historia, ${ }^{5}$ otros en cambio, destacan la incoherencia y el eclecticismo de los diversos autores. Pero, más allá de esta discusión que nos lleva al camino sin salida de la imposibilidad de una clasificación unívoca del corpus, quizás podemos pensar en un vector conductor que atraviesa todos los textos: el efecto de verdad, efecto que ineludiblemente tiene una entidad discursiva, convertida para nosotros en el único objeto pasible de análisis.

${ }^{3}$ Resulta productiva la relación que establece Marc Augé (1998) entre mundos posibles y viajes posibles en ese momento, quizás el último encuentro en la historia de la cultura occidental de dos mundos que se desconocían mutuamente.

${ }^{4}$ Tal como lo desarrolla en este mismo volumen Leonardo Funes.

${ }^{5}$ Remito a Kohut 2009 para un análisis detallado de los distintos modelos que recibieron los cronistas de Indias: a. Los modelos historiográficos prácticos que aportaban el corpus de la historiografía española del siglo XV, los historiadores grecolatinos que habían sido editados y traducidos por esos años y el de la historiografía italiana renacentista. b. Los modelos teóricos desarrollados en los tratados de los humanistas italianos (Colluccio Salutati, Lorenzo Valla, Giovanni Pontano), y españoles (Fernán Pérez del Pulgar y Hernando del Pulgar. Tal como destaca Kohut, el aporte más importante es el pensamiento de Juan Luis de Vives, dado que recoge la herencia antigua clásica y la moderna italiana. El humanista valenciano se ocupa de la historiografía, diferenciando entre poesía e historia, deslinde de los tiempos míticos y los tiempos historiables. Vives previene de la mezcla de verdad y mentiras en los relatos históricos y del estilo bárbaro utilizado por los historiadores medievales, y en la misma línea de pensamiento considera tanto la historia como la poesía subordinadas a la retórica. 
El tratamiento de una materia nunca antes conocida y la exigencia de verdad que deben tener los escritos para ser eficaces se encuentran en el centro de las preocupaciones de los cronistas. En función de esta aspiración se articula el proceso de producción de los textos en cuanto a las reglas de organización del relato, a la primacía de sucesiones espaciales que acercan el relato a las modalidades de los libros de viajes, a las estrategias de fijación cronológica y al empleo utilitario de todas las herramientas que les proporcionaban los postulados de la retórica tanto en los aspectos compositivos como discursivos. ${ }^{6}$ Se retoma en los cronistas de Indias la oposición entre elocuencia y verdad histórica con la preferencia incondicional por ésta última. También se privilegia lo visto y lo vivido, con una profunda credibilidad en las impresiones sensoriales y se menciona la importancia del carácter del historiador, reforzado en la condición de testigo. En este sentido el narrador viajero argumenta que puede contar la verdad porque la vivió; su voz es verdadera porque es producto de la experiencia y los hechos se definen como reales y vividos.

La escritura de la historia supone una consciencia teórica y la vez la produce. Las decisiones que los cronistas debieron tomar en el transcurso de la escritura seguramente no fueron conscientes, ya que muy pocos conocían la preceptiva y las discusiones teóricas de la historiografía de la época, pero subyacen tanto en la utilización de recursos discursivos como en declaraciones explícitas de validación textual. Tanto en los paratextos como en el interior de las crónicas aparecen modelos y conceptos que develan esta conciencia. ${ }^{7}$

Entre la producción textual de este primer período pueden señalarse dos líneas enfrentadas que se adjudican respectivamente la facultad de narrar la "verdad" de la historia de Indias: la de los testigos de la Conquista, ya sean letrados o soldados, y la de quienes escriben desde España, proporcionando una versión de los hechos destinada a ofrecer una narración "objetiva", proveniente de documentaciones escritas o de relatos orales de terceros. Los primeros se arrogan la superioridad de haber sido actores de la gesta y se escandalizan de la soberbia con que personas que nunca pisaron el continente americano relatan los sucesos a papas y emperadores, incurriendo en un sinfín de inexactitudes, sólo con la herramienta que les proporciona su

${ }^{6}$ Véase al respecto el libro de Jimena Rodríguez (2010) que estudia detenidamente la función del relato de viajes en la temprana historiografía de Indias. El viaje, sea real o ficticio, siempre tiene efecto de realidad; la textualización del viaje realizada según modelos medievales, a partir del empleo de una retórica persuasiva, opera como garantía de "objetividad" en las narraciones y en las descripciones.

${ }^{7}$ En el artículo ya citado, Karl Kohut (2009) estudia la concepción teórica historiográfica presente en las crónicas que denomina "fundacionales": Pedro Mártir de Anglería, Gonzalo Fernández de Oviedo, Bartolomé de las Casas, Francisco López de Gómara, Pedro Cieza de León y Bernal Díaz del Castillo. 
elegante estilo. Al respecto puntualiza Gonzalo Fernández de Oviedo en su Historia general y natural de las Indias:

Por cierto yo veo cosas escritas que me maravillo de lo que osaron los auctores decir dellas, arrimados a sus elegantes estilos, seyendo tan desviados de la verdad como el cielo de la tierra, y quedan disculpados con decir: assí lo oí, e aunque no lo vi, entendílo de personas que lo vieron e dieron a entender. $(\mathrm{I}, 14)$.

Por su parte, los segundos consideran que su profesionalismo y la distancia espacial con respecto al escenario de los acontecimientos garantizan la objetividad consustancial a los textos históricos. A esta perspectiva adhiere la crítica cuando se afirma, como en el caso de Antonio de Solís (26) que el relato que hace Bernal Díaz del Castillo de la conquista de México es parcial por su compromiso afectivo con la materia:

Aunque le asiste la circunstancia de haber visto lo que escribió, se conoce de su misma obra que no tuvo la vista libre de pasiones para que fuese bien gobernada su pluma... andan entre sus renglones muy descubiertas la envidia y la ambición.

O la cita de López de Gómara del "Prólogo" de la Crónica de los Corsarios Barbarroja:

Para entender en estas historias he hecho gran diligencia y la hago todavía y haré de aquí adelante para poder de esto decir toda la verdad, sin haber de fingir mentiras y verosimilitudes como hacen los que no alcanzan lo verdadero de las historias y los que escriben cosas antiguas y allá del otro siglo. Muy dificultoso y muy trabajoso es saber la verdad, aun en la historia moderna, cuanto más en la vieja: porque en la una hemos de acudir a lo antiguo y por ventura a lo olvidado y en la otra tomar lengua y noticia de los que se hallaron presentes en las guerras y cosas de las que tratamos, y aun a las veces de quien lo oyó contar al que lo vio, los cuales suelen por odio o por envidia o por gracia y por lisonja, encubrir la verdad, contando las cosas muy al revés de lo que fue. (16)

Ambos posicionamientos resultan hoy reduccionistas, ya que la teoría del discurso y la crítica historiográfica desarrolladas en la segunda mitad del siglo XX han relativizado las aspiraciones a la verdad objetiva en la medida en que se complejizan las relaciones entre los acontecimientos históricos y los múltiples textos que los narran. En este punto es útil recordar a Hayden White (1992) quien recalca que los hechos se limitan a ser, a existir, pero no hablan por sí mismos, necesitan de un discurso que los narre, en cuya construcción se conectan elementos narrativos de diversas procedencias que contribuyen a la producción de un texto con intencionalidades específicas y en el que confluyen 
tradiciones discursivas previas procedentes tanto del ámbito de la historia, como de las ciencias naturales o de la ficción literaria. ${ }^{8}$

Cieza de León y Bernal Díaz defienden en sus crónicas su condición de cronistas soldados, el primero ejerce estas dos funciones simultáneamente y el segundo consecutivamente. En sus argumentaciones re-editan de alguna manera el tópico de las armas y las letras tan caro a la literatura española que podemos remontar a la tradición medieval de Don Juan Manuel, retomada por Cervantes en el Quijote, como muestra de su vigencia en el siglo XVI. También el tópico de la inspiración divina aparece en Cieza, ya que Dios le da la voluntad de escribir la historia. Ambos autores se auto-titulan de pocas letras y ambos oponen la retórica a la verdad a la que se accede a través del estilo llano y no a través del relato ornamentado de las noticias provistas por relaciones, cartapacios o escritos de terceras personas.

Cieza de León afirma:

Aunque vaya esta escriptura desnuda de rethórica, sea mirada con moderación, pues a lo que siento, va tan acompañada de verdad" (1:14)

El cronista confiesa haber trabajado denodadamente, ya que después de las batallas se sometió a los trabajos de la escritura mientras los demás descansaban. Completó, además, lo que no vio, recabando información "de personas de gran crédito, Christianos e Indios", en una perspectiva amplia muy innovadora del discurso colonial que incluye (o pretende incluir para validar su discurso) la voz del otro. ${ }^{9}$

Bernal Díaz del Castillo compone un texto que pretende ser no ya extremadamente realista, sino que aspira a narrar los hechos tal como sucedieron, como es la Historia verdadera de la conquista de la Nueva España. ${ }^{10}$ En primer término cabe destacar que para Bernal el estilo llano es el apropiado para narrar la historia, mientras que las figuras, los colores de la retórica traicionan la verdad y sirven a la fic-

${ }^{8}$ Lejos de la concepción originaria de Roland Barthes (1970) que consideraba que la narrativa podía ser traducida sin menoscabo esencial en comparación con un poema lírico o un ensayo filosófico, la narratología se preocupó por entender al género mismo como una producción de la acción y por diferenciar las marcas lingüísticas que transforman la historia en discurso, en relación con convenciones genéricas o diferentes grados de ficcionalización. Profundizando la problemática, Hayden White (1992) estudia los mecanismos discursivos de la narrativa en tanto metacódigo que permite traducir el conocimiento en relato, y posibilita la configuración de una experiencia en una forma asimilable a estructuras de significación comunes.

${ }^{9}$ Las consecuencias, a veces imprevistas, del contacto entre las visiones del mundo del conquistador y el conquistado conducen a nuevas prácticas discursivas que se experimentan en las crónicas. Véase López Parada (2010: 160).

${ }^{10}$ De ahora en adelante Historia verdadera... Todas las referencias a la obra presentes en este artículo han sido tomadas de la edición de Luis Saínz de Medrano (Díaz del Castillo, 1992). 
ción. Aunque impulsado por sus intereses personales, escribe para la memoria, en estilo llano y con pretensión de objetividad.

Ya en el prólogo, Bernal Díaz pone de manifiesto sus aspiraciones y el lugar desde donde escribe:

...digo y afirmo que lo que en este libro se contiene es muy verdadero, que como testigo de vista me hallé en todas las batallas y reencuentros de guerra... (4)

Como correlato de esta afirmación, el autor considera que la elevación en el estilo lo aleja de la verdad histórica, por eso cultiva la retórica de la llaneza cara a la estética renacentista:

suple la verdad la falta de plática y corta retórica”; “... cuanto a la retórica, que va según nuestro común hablar de Castilla la Vieja e que en estos tiempos se tiene por más agradable porque no van razones hermoseadas ni afectadas que suelen componer los cronistas que han escrito en cosas de guerra, sino toda una llaneza y debajo de decir la verdad se encierran las hermoseadas razones... (915)

En este sentido se diferencia explícitamente de la versión de los mismos acontecimientos proporcionada en la Historia de la conquista de México por Francisco López de Gómara, autor con el que entabla un diálogo antagónico en el desarrollo de la Historia verdadera..., pero a quien seguramente le debe aspectos relativos a la organización y al contenido, en especial detalles anecdóticos quizás refrescados en la memoria gracias a su lectura (Barbón Rodrígue, 1966-67). A poco de iniciado el relato en el cap. XVIII, Bernal Díaz deja constancia de que:

Estando escribiendo esta relación, acaso vi una historia de buen estilo, la cual se nombra de un Francisco López de Gómara, que habla de las conquistas y NuevaEspaña, y cuando leí su gran retórica, y como mi obra es tan grosera, dejé de escribir en ella, y aun tuve vergüenza que pareciese entre personas notables; y estando tan perplejo como digo, torné a leer y a mirar las razones que el Gómara en sus libros escribió, e vi desde el principio y medio hasta el cabo no llevaba buena relación y va muy contrario de lo que fue e pasó en la Nueva-España... (53)

....y diré cómo el cronista Gómara dice que por relación sabe lo que escribe; y esto que aquí digo, pasó así; y en todo lo demás que escribe no le dieron buena cuenta de lo que dice. E esta cosa vea: que para que parezca ser verdad lo que en ello escribe, todo lo que en el caso pone es muy al revés, por más buena retórica que en el escribir ponga. (119-120)

Estas citas dan cuenta del enfrentamiento al que ya he aludido entre narradores testigos y cronistas especializados, para quienes se oponían "verdad recta en la 
narración de los hechos a buena retórica, policía, elocuencia, ornato encumbrado, estilo delicado" (Caillet Bois, 1962: 221).

Para unos y otros cronistas existe la convicción de que la verdad es accesible a la investigación histórica, ya que es factible narrarla. La posibilidad de acceder a la verdad está relacionada con la discusión sobre el estilo: la contienda entre los autores se reduce a definir cuál es la modalidad más apropiada para dar cuenta de la experiencia que se lexicaliza en el discurso para ser mostrada como verdadera. La pregunta a ser respondida podría enunciarse en cómo captar lectores diciendo la verdad y escribiendo bien, sin ceder a la tentación literaria. Por ello, en este sentido, las primeras crónicas interesan desde el punto de vista de las teorías historiográficas actuales por el hecho de que pueden considerarse como un laboratorio (al igual que las crónicas medievales y las humanistas), un espacio de experimentación, un contexto en que la retórica y la preocupación por la lengua y el estilo pasan a ser referenciados. Toda esta discusión se conecta con lo que en las teorías del siglo XX Hyden White denominó el giro lingüístico, o sea el proceso por el cual la historia se convierte en discurso.

\section{La Historia verdadera....: una posible lexicalización de la experiencia}

Considero que en el marco de esta preocupación manifiesta por transmitir "la verdad" de los hechos de la conquista, alejándose de recursos artificiosos, merece atención la presencia de menciones literarias, ubicadas en momentos clave del desarrollo del relato para comprender la función del discurso en la transmisión del proceso histórico. Las escasas concesiones al acervo literario que transmite la prosa de Bernal Díaz pueden resumirse en unos pocos refranes, breves alusiones a personajes de la antigüedad, libros de caballerías y romances. Las menciones corresponden al acervo reducido de un militar instruido que poseía un conocimiento sumario de la cultura vulgata de su época. Por esta razón resulta muy interesante la utilización fluida y reiterativa de recursos muy limitados.

En la Historia verdadera ... se incorporan refranes empleados con función sentenciosa, como el que en el cap. IV aparece en boca del narrador: "que, como dice el refrán, quien acomete, vence" (19). En el cap. LVII, para conectar las acciones de los conquistadores con episodios y protagonistas de la historia universal, se pone en boca de Cortés una sentencia asociada con la figura de Nerón, "Oh, quién no supiera escribir para no firmar muertes de hombres" (156). Esta referencia pone de manifiesto la aproximación que se intenta establecer entre la figura de Cortés y la historia clásica, aún con figuras no especialmente heroicas, seguramente por influencia de modelos discursivos como el texto del mismo López de Gómara. En diferentes pasajes también se compara al capitán español con Julio César, como por ejemplo: 
Y todos a una le respondimos que haríamos lo que ordenase; que echada estaba la suerte e la buena o la mala ventura, como dijo Julio César sobre el Rubicón, (LIX, 159)

Con respecto a los libros de caballerías, me interesa destacar dos referencias al Amadís de Gaula por la valoración dispar que conllevan con respecto de este género. En el capítulo LXXXVII, las tropas españolas se encuentran en las proximidades de Ixtapalapa ya a la vista de México; Bernal Díaz, deslumbrado ante el espectáculo de "tantas ciudades y villas pobladas en el agua, y en tierra firme otras grandes poblaciones" (248), recuerda el comentario general que circulaba entre los soldados: "Decíamos que parecía a las cosas y encantamientos que cuentan en el libro de Amadís" (248). Pero más adelante el narrador se aparta del modelo de la literatura caballeresca al decir, en el capítulo CLI, que va a simplificar el relato porque "de otro modo sería cosa para nunca acabar y parecería a los libros de Amadís e de otros de caballería" (536). Otras alusiones relacionadas con la ficción caballeresca son la referencia en el capítulo CXI a que los prisioneros mientras eran trasladados "iban pensando si era encantamiento o sueño" (335); en el capítulo CCV un soldado se compara con Agrajes, personaje de Amdadís de caracterizado por sus brabuconadas (869); y finalmente el autor afirma haber leído La destrucción de Jerusalem (CLVI, 573). ${ }^{11}$

Sin lugar a dudas Bernal Díaz no es un autor letrado que ha bebido directamente de las fuentes de la literatura clásica y medieval. Seguramente a lo largo de su vida ha leído pocos libros y a otros accedió por referencias indirectas. Pero más allá de la interrogación sobre cuántos y cuáles fueron sus lecturas, el cronista comparte con sus contemporáneos un bagaje de relatos históricos, literarios y filosóficos, a los que sabe acudir para causar empatía en sus lectores. En este juego de involucrar al receptor con el punto de vista del narrador a partir del empleo de determinados modelos compartidos, creo que el empleo del género romance resulta el más eficaz.

Las referencias al romancero también aparecen asimiladas a la narración de los acontecimientos e ilustran la confluencia de materia narrativa y convenciones genéricas de distinta procedencia en la creación del discurso cronístico americano. Con el propósito de esclarecer ese proceso propongo recorrer en la Historia verdadera... la presencia de versos de romances integrados al texto historiográfico, para analizar el significado que adquieren en el nuevo contexto discursivo ${ }^{12}$ y poner de manifiesto la forma en que se establecen posibles diálogos con otros textos históricos y ficcionales, volviendo poco productiva esta última distinción.

${ }^{11}$ Beatriz Pastor (1983) y Luis Sainz de Medrano (Díaz del Castillo, 1992: 47) acercan a la figura de Cortés con la del Cid del Cantar, en especial por su mesura, comparación que considero forzada ya que el texto no aporta elementos suficientes para sustentarla.

${ }^{12}$ Una versión preliminar de este rastreo fue publicada en Chicote 1998. 
Desde épocas tempranas, en las primeras décadas del siglo XVI, el romance llega al continente americano. En la interrelación constante entre oralidad y escritura que caracteriza a la cultura renacentista (herencia recibida, a su vez, del universo medieval), el romance se difunde tanto a viva voz, a través de los hombres de guerra y de paz que llegan al Nuevo Mundo, como en los romanceros y pliegos sueltos que se embarcaron en la primera etapa de dominación española.

Ya Menéndez Pidal (1953: II, 226) señalaba la fuerte incidencia que los textos de romances tuvieron en los primeros cronistas, quienes se valieron de ellos para comunicar las experiencias vividas:

Bien podemos decir con seguridad que un copioso romancero pasó a América en la memoria de aquellos que tripulaban las naves descubridoras y en el recuerdo de cuantos después allá fueron. La noticia precisa acude en cuanto hallamos un cronista algo inclinado al pormenor pintoresco.

A través de una detallada documentación, Menéndez Pidal devela la memoria romancística de los cronistas de Indias, citando múltiples ejemplos de romances recitados por conquistadores de la talla de Cortés o Almagro, referidos, además, a episodios clave del desarrollo de la lucha contra los indios. En la presentación del tema que Menéndez Pidal ofrece tanto en Los romances de América y otros estudios (1939), como en el Romancero Hispánico (1953), no cuestiona la veracidad histórica de las pruebas que aduce, en el sentido de que no se plantea si los versos de romance fueron efectivamente expresados por los conquistadores, o si fueron agregados por los cronistas con la finalidad de ornamentar el discurso histórico que intentaban producir.

Con referencia a esta posible segunda interpretación de la inclusión de romances en las crónicas, Ana Valenciano (1992: 49) considera que:

las pruebas aducidas por Menéndez Pidal para verificar la inmediata llegada del Romancero viejo a Hispanoamérica, han sido unánimemente aceptadas por los estudiosos de esta tradición, pero la revisión de los distintos pasajes cronísticos en que aparecen las citas romancísticas nos lleva a reflexionar acerca de la posible utilización del romancero como uno más entre los recursos estilísticos usados por los cronistas en la redacción de sus obras.

Valenciano interpreta que la reproducción de versos o fragmentos de romances (al igual que las referencias a libros de caballería o al cancionero y refranero populares) habrían servido para ornamentar con matices literarios unas obras de innegable intención noticiera. Si bien comparto el punto de vista de Valenciano, considero que, de todos modos, bien demos por sentado que los romances surgieron de la boca de los protagonistas de la gesta americana, o bien consideremos que fueron empleados por los historiadores como recurso estilístico, su misma mención no deja dudas sobre la pertenencia del género al patrimonio cultural compartido por cronistas y 
conquistadores. Tampoco ofrece cuestionamiento la necesidad que tuvieron los escritores del siglo XVI de acudir a modelos discursivos fijados y conocidos por todos para transmitir una realidad que poco remitía a los mundos posibles y mucho se acercaba a las construcciones fantásticas de la literatura idealizante.

Por esta razón los romances comparten con las novelas de caballerías los primeros puestos en las estadísticas de textos literarios mencionados en las obras de temática americana y en las listas de libros enviados al Nuevo Mundo en el transcurso del siglo XVI. En su estudio sobre el romancero colombiano, Gisela Beutler estudia el envío de romances a Colombia en ese período y encuentra notaciones semejantes para Buenos Aires; de ello se infiere que estas remesas se efectuaron a todos los lugares del imperio colonial, constituyendo de este modo, un vínculo en la tradición americana, que se puede constatar en las recolecciones modernas (Beutler, 1977: I; Menéndez Pidal, 1953: II, 231). Leonard (1979) ${ }^{13}$ y Torre Revello (1940) en sus respectivos estudios dedicados a la bibliografía que llegó a América, señalan que, a pesar de la prohibición de enviar literatura de ficción a partir de $1559,{ }^{14}$ estos textos siguieron apareciendo en los registros de envíos. Ambos autores coinciden también en afirmar que la lectura de estos textos, realizada posiblemente en conjunto, por un soldado que leía ante una rueda de oyentes las aventuras relatadas, tuvo gran parte de sugestión en el momento en que se constituyeron los valores heroicos de la conquista. Novelas de caballerías y romancero aportaron el marco idealizante en el que se insertaron las aventuras del nuevo mundo, ofreciendo la posibilidad de traducir las vivencias a cánones culturales conocidos por los conquistadores. ${ }^{15}$

Los cronistas de Indias pusieron en boca de los conquistadores los versos del romancero viejo. Las crónicas escritas en prosa con finalidad informativa incluyeron fragmentos de romances, en tanto intertexto perteneciente a un universo cultural compartido. ${ }^{16}$

${ }^{13}$ Leonard (1979: 215) menciona a los "omnipresentes romanceros", y rastrea su aparición en bibliotecas particulares, en envíos a México, Perú y Panamá.

${ }^{14}$ A partir de 1559 se prohíbe el envío a América de literatura de ficción, especialmente los incluidos en los sucesivos índices, debido a que se había divulgado la leyenda de una capacidad lectora irrefrenable de los indios alfabetizados. A pesar de las prohibiciones expresamente promulgadas, las "mentirosas historias", siguieron llegando y dejaron las famosas cédulas como "las hostias sin consagrar". Los alguaciles inquisitoriales eran tolerantes con la literatura mientras que controlaban especialmente las obras que afectaban a la fe y el dogma, comprendidas en los índices eclesiásticos.

${ }^{15}$ Es importante hacer referencia a que en el siglo XVII el primer lugar en los registros de envíos lo ocupa el Quijote, texto que también recoge la influencia de los géneros señalados, y que replantea las relaciones entre ficción y realidad.

${ }^{16}$ Por otra parte, las noticias cronísticas se ven reforzadas con algunos datos que nos informan de la temprana importación de un consistente número de pliegos sueltos y cancionerillos y con las referencias encontradas en obras de autores cultos entre los que cabría desta- 
En el presente conjunto de observaciones mi interrogante se centra en dilucidar cuál es la función que cumplen las menciones romancísticas en la Historia verdadera..., con qué finalidad se incluyen, y si son incorporados a la escritura como rasgos de oralidad que contribuyen a la ficcionalización, o, si por el contrario, infunden veracidad histórica a los hechos narrados.

En primer término, antes de interiorizarnos en los casos particulares en que aparecen romances, merece ser destacado el hecho de que el discurso histórico producido por Bernal Díaz del Castillo tiene caracteres que lo acercan al relato autobiográfico, a la fijación de hechos vividos narrados en primera persona por un testigo presencial. Existe, por lo tanto, una intención valorativa de los sucesos que alejan al relato de su pretendida objetividad histórica, y no se desechan materiales narrativos de variada procedencia, como leyendas, relatos de costumbres, etc. Al considerar este discurso cronístico, estamos frente a la acción vivida de los acontecimientos históricos que se transmite a través de la narración de esos hechos, dando lugar no a una mera traducción de códigos comunicativos sino a una reconstrucción del hecho en sí, que implica una estructura portadora de un nuevo significado en su modo de fijación textual.

La revisión de la aparición de romances en la prosa cronística nos da la posibilidad de ejemplificar este proceso. Una de las posibilidades de inclusión del romance en las crónicas es que la mención romancística valide la reproducción del discurso directo, y de este modo acerque el relato a los hechos vividos.

En su Historia Verdadera..., Bernal Díaz incorpora romances a lo que pretende ser la reproducción del habla coloquial de Hernán Cortés, a juzgar por la forma en que los presenta intercalados en narraciones y fragmentos dialogados:

\begin{abstract}
Paréceme, señor, que os han venido diciendo estos caballeros que han venido otras dos veces a estas tierras: 'Cata Francia, Montesinos, cata París la cibdad/ cata las aguas de Duero, do van a dar a la mar'; yo digo que miréis las tierras ricas, y sabeos bien gobernar. Luego Cortés entendió a qué fin fueron aquellas palabras dichas, y respondió: 'denos Dios ventura en armas como al paladín Roldán', que en lo demás, teniendo a vuestra merced y a otros caballeros por señores, bien me sabré entender."(XXXVI, 101).
\end{abstract}

Los versos del romancero viejo aparecen en un momento clave del desarrollo de la acción bélica, convertidos a su vez en clímax del desarrollo narrativo. La cita de los romances de Montesinos y Gaiferos es tan oportuna que, en medio de los versos de romance, Cortés decide desobedecer las órdenes de Diego Velázquez, gobernador de Cuba, y conquistar México.

car a Hernán González de Eslava (1534-1601), que en sus Coloquios espirituales y sacramentales, cita o contrahace treinta romances viejos (González de Eslava, 1989). 
Más adelante (LXIX), Bernal Díaz hace recurrir a Cortés al acervo romancístico, cuando sus soldados están desalentados ante las vicisitudes de la lucha:

... y Cortés respondió, medio enojado, que valía más morir por buenos, como dicen los cantares, que vivir deshonrados. (191)

Los mismos versos del romance de Roldán en Roncesvalles, con variante discursiva incluida, son recordados como remate de la arenga pronunciada por Cortés antes de la lucha contra Pánfilo de Narváez (CXXII):

\begin{abstract}
Así, señores, pues nuestra vida y honra está, después de Dios, en vuestros esfuerzos e vigorosos brazos, no tengo más que os pedir por merced ni traer a la memoria, sin que en esto está el toque de nuestras honras y famas, para siempre jamás y mas vale morir por buenos que vivir afrentados. (CXXII, 368)
\end{abstract}

Los romances se resemantizan al adaptarse a la nueva problemática histórica. Sirven como modelos interpretativos de la realidad que debe afrontarse: la muerte que fue preferible al deshonor para los héroes de Roncesvalles, tiene un valor ejemplar para los protagonistas de la gesta americana. Por otra parte, la inclusión de variantes discursivas evidencia la vitalidad que tenía el género en el ámbito de la oralidad.

En el desarrollo de la Historia verdadera... nuevamente se ponen versos de romance en boca de Cortés y de Gonzalo de Salazar, quien habiendo fracasado en un desarrollo argumentativo en el que advertía a su jefe del peligro futuro, decide cortar la tensión con los versos de un romance carolingio desconocido:

y decía en los cantares '¡Ay tío, volvamonós, ay tío, volvamonós!. A lo que Cortés respondía cantando: '¡Adelante, mi sobrino, adelante, mi sobrino! Y no creáis en agüeros que será lo que Dios quisiere. Adelante, mi sobrino!' (CLXXIV, $711)^{17}$

Alusiones y fraseología sirven al cronista como recursos discursivos para hacer inteligible la inédita experiencia de vida que está protagonizando. Se recurre a la fraseología lexicalizada de los romances, a un discurso con alto valor figurativo, que tiene además la ventaja de ser compartido con los receptores de la crónica. A través de un conjunto de estructuras discursivas que proceden de ámbito ficcional, se valida la función noticiera del relato. La integración de la fraseología romancística como discurso lexicalizado a la prosa de las crónicas fue posible ya que los versos funcionaban previamente entre la comunidad portadora del género como ele-

${ }^{17}$ Como bien señala Menéndez Pidal (1953: II, 228, n.53), Díaz prosifica los versos integrándolos al discurso cronístico. 
mentos estructurados de la competencia lingüística, en los ámbitos de la lectura, el canto y la oralidad, en forma conjunta (García de Enterría, 1988).

En último término considero la mención romancística que aparece en el capítulo CXLV en referencia a un fracaso de las tropas españolas que habían salido huyendo de la ciudad de México. En primer término el cronista ilustra el relato con un romance noticiero de factura americana referido a Hernán Cortés, tantas veces aludido en enfoques americanistas del romancero, ${ }^{18} \mathrm{y}$ a continuación se cita el romance de materia clásica "Mira Nero de Tarpeya", en referencia dialógica con la obra de Fray Bartolomé de las Casas, aunque con signo opuesto.

...y en ese instante suspiró Cortés con una muy gran tristeza, muy mayor que la que antes traía, por los hombres que le mataron antes que en alto cu subiese; y desde entonces dijeron un cantar o romance:

En Tacuba está Cortés Con su escuadrón esforzado

Triste estaba y muy penoso Triste y con gran cuidado,

La una mano en la mejilla, Y la otra en el costado, etc.

Acuérdome que entonces le dijo un soldado que se decía el bachiller Alonso Pérez, que después de ganada Nueva España fue fiscal y vecino de México: Señor capitán, no esté Vuestra Merced tan triste, que en las guerras estas cosas suelen acaecer, y no se dirá por vuestra merced: Mira Nero de Tarpeya a Roma cómo se ardía. (CXLV, 501).

En realidad la cita de Bernal Díaz es respuesta, en diálogo contrapuntístico, con fray Bartolomé de las Casas, ya que en la Brevísima relación de la destrucción de Indias el mismo romance es puesto en labios de Cortés en un contexto totalmente diferente. Las visiones enfrentadas en torno a la figura de Cortés reeditan las perspectivas antagónicas de los hechos de la Conquista que representan Bernal Díaz y Fray Bartolomé de las Casas: mientras que el Obispo de Chiapas abandera la defensa de la nueva legislación antiesclavista de 1545, Bernal Díaz, en cambio, aspira a

${ }^{18}$ En Perú también aparecen romances creados para referirse a situaciones históricas, como el que relata el trágico final del rebelde Hernández de Girón protagonizado por él mismo y su esposa, Doña Mencía, "En el Cuzco, esa ciudad, grande gente se juntó" Emilia Romero (1952: 22) edita el romance de factura culta, que incorpora versos de reminiscencias tradicionales. El poema fue compuesto para recordar la derrota del personaje histórico y la despedida final que antecede las penurias pasadas por la dama después de la muerte de su esposo. Otro romance citado por Romero (1952: 17) es el que compone Alonso Enríquez referido a la muerte de Diego de Almagro, el cual debe cantarse "al tono de el Buen Conde Hernán González". Dichos romances históricos de factura americana tienen la particularidad de no haberse tradicionalizado, ya que para estos textos no se ha documentado una vida posterior en variantes. 
conservar los derechos de los primeros conquistadores de esclavizar y señorear las encomiendas a perpetuidad. Después de la matanza de los indios conjurados en Cholula, las Casas (1982: 103) ornamenta su relato con clara intencionalidad de denigrar al causante de los hechos:

dícese que, estando metiendo a espada los cinco o seis mil hombres, estaba cantando el capitán de los españoles:

Mira Nero de Tarpeya a Roma cómo se ardía, gritos dan niños y viejos y él de nada se dolía.

En el cap. LXXXIII Bernal Díaz justifica la matanza y atribuye la mayor responsabilidad a los jefes tlastaltecas, a modo de respuesta a las Casas:

Pasemos adelante y digamos que estas fueron las grandes crueldades que escribe nunca acaba de decir el señor obispo de Chiapa, don Fray Bartolomé de las Casas; porque afirma y dice que sin causa ninguna, sino por nuestro pasatiempo y porque se nos antojó, se hizo aquel castigo; y aun dícelo por arte en su libro a quien no lo vio ni lo sabe, que les hará creer que es as'aquello y otras crueldades que escribe, siendo todo al revés, y no pasó como lo escribe... (235)

Asistimos a una evidente manipulación del poema. El mismo romance es utilizado con la intención de definir dos caracterizaciones opuestas de un personaje histórico: su calidez humana y su crueldad. La gran popularidad del romance de Nerón permitió su inclusión en uno y otro pasaje. La alusión al incendio de Roma como una situación de desastre se homologaba con los acontecimientos mexicanos, pero más allá de esa similitud general, considero que una lectura atenta del romance permite establecer que su contenido no se adecua estrictamente a ninguno de los dos contextos en que aparece. Bernal Díaz alude a un momento de tristeza de Cortés ante la matanza de sus hombres que no condice con la ausencia de culpa en el personaje del romance, quien "de nada se dolía", verso que por otra parte no es citado por el cronista, quizás consciente de la incongruencia de sentido. Bartolomé de las Casas lo emplea, ya en cita más extensa para referirse a la crueldad de Cortés, pero tal como señala Menéndez Pidal (1953: II, 227-228), no repara en que el romance no queda bien en boca del que no se dolía, sino de aquel que acusa la conducta equívoca, o sea en la construcción discursiva del cronista que decide emplear el romance para ilustrar la acción narrada.

Pueden ser realizados rastreos semejantes del empleo de romances en otras crónicas. ${ }^{19}$ He querido en esta oportunidad presentar sólo algunos de la Historia verda-

${ }^{19}$ Ejemplos válidos también se pueden extraer de las crónicas referidas a la Conquista del Perú. En el relato de los episodios referidos a la conquista de Perú hallamos otro ejemplo de inclusión de un verso de romance en una situación de tensión narrativa con el propósito 
dera... que considero relevantes con el objetivo de demostrar la compleja interacción de los códigos de oralidad y escritura en estas alusiones y sus variados matices funcionales en la estructuración del discurso.

Cabe señalar una vez más la capacidad de los versos romancísticos que, en tanto frases lexicalizadas, portadoras de un plus de significado, pueden, más allá de su contexto, ingresar en nuevos circuitos discursivos con contenidos diferentes. Desde esta perspectiva la Historia verdadera... puede ser estudiada como receptáculo de diferentes estratos discursivos previos, pero también, proyectada hacia el futuro, como texto fundacional de un nuevo lugar y un nuevo tiempo. En las páginas de Bernal Díaz el romancero actúa como intertexto literario presente en el texto historiográfico con el objetivo de validar la verdad, e inaugura una presencia ininterrumpida del género en la literatura y la cultura latinoamericana que continúa hasta el presente.

\section{BIBLIOGRAFÍA}

AUGÉ, Marc.

1998 El viaje imposible. El turismo y sus imágenes. Barcelona: Gedisa, Bauman, Richard y Charles Briggs.

de validar el relato. Antonio de Herrera y Cieza de León (Romero, 1952:14) cuentan como en la reunión que se realizó entre Pizarro y Almagro en 1537, éste último toma conocimiento de las intenciones que tenía Pizarro de apresarlo, porque uno de los suyos se lo advierte cantando el romance de la Infanta seducida, "Tiempo es el caballero tiempo es de andar de aquí". Con lo que Almagro entendió y buscó una excusa para retirarse de regreso a su real. Este ejemplo corrobora el valor altamente referencial del romancero, y la capacidad de los versos de resemantizarse para adaptarse a nuevos contextos situacionales. El verso aludido, que en el texto del romance aparece relacionado con los reclamos que la niña hace a su seductor, se resignifica convirtiéndose en una advertencia cómplice entre compañeros de armas. Este fenómeno de descontextualización y recontextualización (Bauman- Briggs, 1990) es posible debido a la movilidad de los segmentos discursivos del romance y la extrema popularidad que gozaba el género en la época que permitió que el canturreo de Francisco de Godoy no asombrara a nadie y que tuviera el valor de un mensaje secreto. Queda al margen de mis especulaciones el cuestionamiento acerca de la veracidad del hecho; estas reflexiones sólo me conducen a conferirle un alto grado de verosimilitud. La presencia del romancero en la cultura de la época como literatura oralizada que cumplía la función de entretener, se evidencia en la anécdota relatada en términos semejantes por Diego Fernández y Pedro Gutiérrez de Santa Clara, referida al conquistador del Perú, Francisco de Carvajal, famoso por su maldad y por su sentido del humor. Se cuenta que, estando a punto de morir se le llevó un sacerdote a prisión con la finalidad de que lo confesase y él lo entretuvo preguntándole por los romances de Gaiferos y el Marqués de Mantua, como el padre negara conocerlos, le mandó que los aprendiera para que se los cantara mientras él estuviera enfermo (Romero, 1952, 15). 
1990 "Poetics and Performance as Critical Perspectives on Language and Social Life", Anual Review of Anthropology, 19, pp. 59-88.

BARBÓN RODRÍGUEZ, José A.

1966-67 "En torno a la crítica sobre Bernal Díaz del Castillo", Revista de Historia Americana y Argentina, VI; 11 y 12, pp. 58-60.

BARTHES, Roland.

1970 Análisis estructural del relato. Buenos Aires: Tiempo Contemporáneo.

BEUTLER, Gisela.

1977 Estudios sobre el Romancero Español en Colombia. Bogotá: Instituto Caro y Cuervo.

CAILlet BoIs, Julio.

1962 "Bernal Díaz del Castillo o de la verdad histórica", Revista Iberoamericana, XXI, pp. 199-228.

CIEZA DE LEÓN, Pedro de.

1991 Crónica del Perú. Lima: Pontificia Universidad Católica del Perú. CHICOTE, Gloria B.

1998 "El romance en las Crónicas de Indias: nuevos mundos narrados con viejos textos", en Actas del IV Congreso Internacional AISO, Alcalá de Henares: Universidad, pp. 501-508.

1999 "Yo me estando en Giromena": un proceso de descontextualización inconcluso, en Inés de Castro. Studi. Estudos. Estudios. Patrizia Botta (ed.). Ravenna: Longo Editore, pp. 55-66.

2006 "Historiografía y romancero: tensiones discursivas en las representaciones textuales de Pedro I de Castilla", Incipit, XXV - XXVI: $1123-1145$.

2007 "Las colecciones rioplatenses de Robert Lehmann-Nitsche: panóptico de la literatura popular", en El vendaval de lo nuevo. Literatura y cultura en la Argentina moderna entre España y América Latina, 1880-1930. Gloria Chicote y Miguel Dalmaroni (eds.).

2009 "Memorias de ultramar: actualidad europea en la Biblioteca Criolla (1880 - 1925) de Robert Lehmann-Nitsche", en Contratiempos de la memoria en la literatura argentina. Miguel Dalmaroni- Geraldine Rogers (eds.). La Plata: Edulp, pp. 41-60.

2010 “'Entre las gentes se dize, mas no por cosa sabida'. Ficcionalización, propaganda y manipulación del mensaje en el Romancero de Pedro el Cruel", en Expresiones de la cultura y el pensamiento medievales. Lillian von der Walde Moheno, Concepción Company y Aurelio González (ed.). Publicaciones de Medievalia 37. México: El Colegio de México-Universidad Nacional Autónoma de México-Universidad Autónoma Metropolitana, 2010, pp. 189-205. 
DíAZ DEL CASTILlo, Bernal.

1992 Historia verdadera de la conquista de la Nueva España. Intr. y notas de Luis Sáinz de Medrano. Barcelona: Planeta.

2005 Historia verdadera de la conquista de la Nueva España. Intr. y ed. de José Barbón Rodríguez. México: El Colegio de México-UNAM.

FERNÁNDEZ DE OVIEDO, Gonzalo.

1959 Historia general y natural de las Indias. Madrid: Biblioteca de Autores Españoles.

FERRÉ DA PONTE, Pedro.

1983 "El romancero tradicional y la historiografía", en Literatura y Folklore: Problemas de intertextualidad. Alonso Hernández (ed.). Salamanca: Universidad de Salamanca-Universidad de Groningen, pp. 131-147.

GARCÍA DE ENTERRÍA, María Cruz.

1988 “Romancero: ¿cantado-recitado-leído?”, Edad de Oro VII, pp. 89104.

GONZÁLEZ DE ESLAVA, Fernán.

1989 Villancicos, romances, ensaladas y otras canciones devotas. Margit Frenk (ed.). México: El Colegio de México.

KoHUT, Karl.

2009 "Las primeras crónicas de Indias y la teoría historiográfica", Colonial Latin American Review, vol. 18, n 2, pp. 153-87.

LAS CASAS, Bartolomé de.

1982 Brevísima relación de la destrucción de Indias. Madrid: Cátedra.

LEONARD, Irving.

1979 Los libros del conquistador. México: FCE.

LÓPEZ DE GÓMARA, Francisco.

1989 Crónica de los corsarios Barbarroja. Madrid: Polifemo.

LÓPEZ PARADA, Esperanza.

2010 "Las voces del otro: transculturación, escritura y resistencia", en Cristóbal de Molina, Relación de las fábulas y ritos de los Incas. Paloma Jiménez del Campo (ed.). Madrid: VervuertIberoamericana, pp. 153-198.

MENÉNDEZ PIDAL, Ramón.

1939 Los romances de América y otros estudios. Buenos Aires: EspasaCalpe.

1953 Romancero hispánico (hispano- portugués, americano y sefardi) Teoría e historia. Madrid: Espasa-Calpe.

PASTOR, Beatriz.

1983 Discurso narrativo de la Conquista de América.La Habana: Casa de las Américas. 
RODRÍGUEZ, Jimena.

2010 Conexiones transatlánticas. Viajes medievales y crónicas de la conquista de América. México: El Colegio de México

ROMERO, Emilia.

1952 El romance tradicional en el Perú. México: El Colegio de México. Solís, Antonio de.

1944 Historia de la conquista de México. Buenos Aires: Emece, 2 vols. TORRE REVELLO, José.

1940 El libro, la imprenta y el periodismo en América. Buenos Aires. VALENCIANO, Ana.

1992 "El romancero tradicional en la América de habla hispana", Anales de Literatura Hispanoamericana, vol. 21, pp. 145-163.

(en prensa) "De la crónica al romance: el proceso de transformación de un personaje histórico", en Actas del XVII Congreso de la Asociación Internacional de Hispanistas, Roma: 2010.

WHITE, Hayden.

1992 "El valor de la narrativa en la representación de la realidad", en $E l$ contenido de la forma: narrativa, discurso y representación históri$c a$. Barcelona: Paidós. 